\title{
Alkali-Aggregate Reactions in Concrete: Methodologies Applied in the Evaluation of Alkali Reactivity of Aggregates for Concrete
}

\author{
A. Santos Silva ${ }^{1, a ;}$ D. Soares ${ }^{1, b} ;$ L. Matos ${ }^{1, c} ;$ I. Fernandes ${ }^{2, d} ;$ M. Salta ${ }^{1, e}$ \\ 'National Laboratory of Civil Engineering, Av. do Brasil 101, 1700-066 Lisbon, Portugal \\ ${ }^{2}$ FCUP, Universidade do Porto, DGAOT/Centro de Geologia, Porto

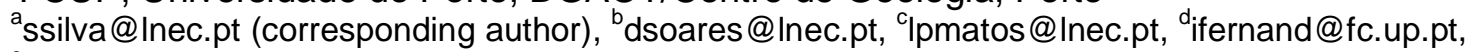 \\ emsalta@Inec.pt
}

\begin{abstract}
The alkali-aggregate reaction (AAR) in concrete is a group of chemical reactions that involves the reaction of certain minerals present in the aggregates with alkali and hydroxyl ions in the interstitial solution of cement paste in concrete. These reactions form an alkaline hygroscopic gel that absorbs water and expands causing internal stresses with cracking [1].

The AAR mitigation measures oblige the correct evaluation of the alkali reactivity of the aggregates. This is normally assessed by petrographic, chemical or expansion test methods.

Several studies regarding alkali reactivity of aggregates for concrete structures in Portugal, including bridges and dams, indicated that their field performance does not correspond to the previously performed evaluation.

Presently, Portuguese methodology is based on the LNEC Specification E461-2007, which shows some limitations regarding rock types such as granitoids [2]. This situation motivated the development of a research project, involving medium and long term expansion tests in different conditions, under accelerated and natural exposure conditions, as well as petrographic evaluation of the main Portuguese aggregates used/to be used in concrete. This paper presents the preliminary results of this research.
\end{abstract}

Keywords: ASR; aggregates; alkali reactivity, concrete.

\section{References}

[1] Santos Silva, A., (2005), "Degradation of concrete by alkali-silica reaction. Use of fly ash and metakaolin for its prevention. (in Portuguese)", Ph.D. Thesis, LNEC/ Minho University.

[2] LNEC E 461, 2007, "Betão. Metodologias para prevenir reacções expansivas internas", Especificação LNEC, Lisboa, p. 7. 